\title{
Oliguria after prophylactic ureteric stenting in gynaecological surgery-a report of three cases and review of the literature
}

\author{
Anita J. Merritt • Ilze Zommere • Richard J. Slade • \\ Brett Winter-Roach
}

Received: 5 June 2013 / Accepted: 19 December 2013 / Published online: 17 January 2014

(C) Springer-Verlag Berlin Heidelberg 2014

\begin{abstract}
Ureteric injury is one of the most serious complications of gynaecological surgery. Use of prophylactic preoperative bilateral ureteric stents to reduce ureteric injury is established in colorectal surgery and becoming commonplace in complex gynaecological surgery. The safety of the procedure has been questioned due to reports of stent-induced complications including a rare but serious phenomenon of stent-induced transient obstructive oligo-anuria termed reflex anuria, a response to manipulation and irritation of the ureters. A retrospective case-note review of patients who had bilateral ureteric stents placed prior to gynaecological surgery at Salford Royal Hospital, UK, from 2007 to 2011 was performed to identify cases of oligo-anuria post-stenting, which were not related to hypovolaemia, nephrotoxic drugs or a radiologically evident obstruction. All patients had their stents removed immediately at the end of surgery before leaving the operating theatre. Three out of 439 patients $(0.7 \%)$, who had preoperative bilateral ureteric stents, developed post-operative oligo-anuria despite relatively normal radiological assessment. In these three cases outlined below, one self-resolved, and two required urgent re-stenting to relieve obstruction. Use of ureteric stents for major gynaecological surgery can expedite intraoperative identification of the ureters to help reduce accidental ureteric injury but can directly cause complications. These three cases have contributed to knowledge of the complications of ureteric stents during major gynaecological surgery. Awareness of reflux anuria as a possible root cause of post-operative acute renal failure is important for guiding appropriate and timely management to preserve renal function.
\end{abstract}

\footnotetext{
A. J. Merritt $(\bowtie) \cdot$ I. Zommere $\cdot$ R. J. Slade $\cdot$ B. Winter-Roach Department of Gynaecology, Salford Royal Hospitals NHS Trust, Stott Lane, Salford M6 8HD, UK

e-mail: anita.merritt@doctors.org.uk
}

Keywords Ureteric stents · Catheterization · Reflex anuria · Renal failure

\section{Background}

Ureteric injury during gynaecological surgery can be associated with significant morbidity [1]. This injury rate is approximately $1 \%$ but is particularly associated with abdominal hysterectomies and more complex surgery involving exenterative procedures [2]. Preoperative insertion of ureteral catheters/stents to aid identification of the ureters and avoid injury and/or enhance intraoperative recognition of injury and repair is becoming more common in gynaecology and other surgical disciplines.

Whether or not the use of stents actually helps prevent ureteric injury is controversial. Some studies have found that using stents reduced the injury rate [3], whereas others do not find any clear benefit $[4,5]$. A large randomised controlled trial of 3,141 women who were randomised to prophylactic bilateral ureteral catheterization versus no catheters showed a similar low incidence of ureteral injury in both groups; however, severe injury was less common in women with ureteral catheterization [5].

The procedure of catheterization and stent insertion per se is associated with complications [6]. Urinary tract infection is common but can be reduced by perioperative antibiotics and early stent removal. Macrohaematuria, dysuria, urgency, pain and fever are particularly associated by stents left in for increased time. There are also rare reports of anuria and acute renal failure as a complication of ureteric catheterization.

During a 5-year period from 2007 to 2011, 439 patients had prophylactic ureteric stents prior to major gynaecological surgery at Salford Royal Hospital, UK. All stented patients had the stents removed immediately at the end of the surgery. Of these, three $(0.7 \%)$ developed anuria and acute renal 
failure not linked to hypovolaemia or acute tubular necrosis, but of a transient obstructive nature, but with relatively normal radiological assessment. These three cases are described.

\section{Case 1}

An 82-year-old lady with obesity, hypertension ischemic heart disease and diabetes presented with post-menopausal bleeding. Investigations confirmed an endometrial carcinoma, and she underwent total abdominal hysterectomy and bilateral salpingo-oophorectomy with preoperative bilateral ureteric stenting.

There were no intraoperative complications and no difficulties during stent insertion, but directly after the stents were removed at the end of surgery, gross haematuria was noted. On day 1, post-op haematuria persisted but urine output, vital observations and biochemistry investigations were within normal limits.

On day 2, the patient complained of bilateral groin pain and had persistent haematuria, and despite intravenous fluid challenges, urine output declined to $20 \mathrm{ml} / \mathrm{h},(24 \mathrm{~h}$ fluid balance: $3,224 \mathrm{ml}$ in/490 $\mathrm{ml}$ out). She then developed pulmonary oedema, and investigations revealed metabolic acidosis, urea $7.9 \mathrm{mmol} / \mathrm{l}$, and creatinine $184 \mu \mathrm{mol} / \mathrm{l}$. A renal tract ultrasound scan showed only mild bilateral hydronephrosis with no site of obstruction or ureteric dilation, and the cause of the oliguria was unclear (Fig. 1b).

Day 3 was a worsening clinical picture $(24 \mathrm{~h}$ fluid balance: $1,450 \mathrm{ml}$ in $/ 49 \mathrm{ml}$ out, creatinine $339 \mu \mathrm{mol} / 1$, urea $15.55 \mathrm{mmol} / \mathrm{l}$ ), and since post-renal obstruction was considered the most likely cause of the acute renal failure, cystoscopy with bilateral ureteric stenting was performed. The stents were inserted with ease and resulted in dramatic diuresis (7 1 over $24 \mathrm{~h}$ ) and much improved renal function tests. The ureteric stents were left in situ for 10 weeks, after which they were removed without further complications.

\section{Case 2}

A premenopausal woman with a high grade ovarian malignancy was admitted for total abdominal hysterectomy with right salpingo-oophorectomy with preoperative bilateral ureteric stenting. The stents were removed at the end of surgery. On day 1, post-op urine output was within normal limits (24 h fluid balance: $3,300 \mathrm{ml} \mathrm{in} / 2,310 \mathrm{ml}$ out), and there was no evidence of haematuria. On day 2, post-op urine output decreased $(24 \mathrm{~h}$ fluid balance: $2,550 \mathrm{ml}$ in/480 $\mathrm{ml}$ out), and the patient complained of severe abdominal and back pain, associated with nausea and vomiting, pyrexia, and rise in creatinine to $202 \mu \mathrm{mol} / \mathrm{l}$ and urea to $5 \mathrm{mmol} / \mathrm{l}$. A CT scan of the abdomen and pelvis showed mild prominence of the pelvicalyceal collecting system and proximal ureters bilaterally tapering to normal calibre in the upper third with no evidence of obstruction or extrinsic compression (Fig. 1a).

In light of the clinical and biochemical findings, and experience from case 1 (above), an obstruction of the renal tract was still suspected, and she underwent cystoscopy and bilateral ureteric stents on day 3 post-op, after which the creatinine and urea rapidly decreased to $66 \mu \mathrm{mol} / 1$ and $3.6 \mathrm{mmol} / \mathrm{l}$, respectively, and the normal urine output returned $(24 \mathrm{~h}$ fluid balance: $3,200 \mathrm{ml}$ in/1,726 ml out). The stents remained in situ for 3 weeks, after which her renal function remained normal.

\section{Case 3}

A lady in her 70s' with endometrial cancer was admitted for laparotomy, hysterectomy and bilateral oophorectomy with

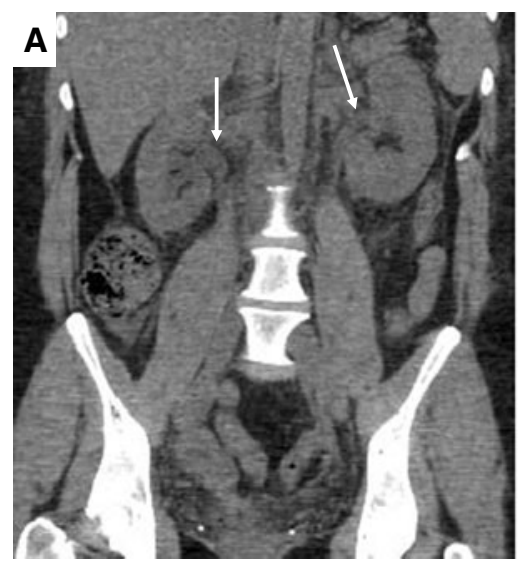

Fig. 1 a Computed tomography (CT) of the abdomen and pelvisunenhanced image, from case 2 showing mild prominence of the pelvicalyceal collecting system and proximal ureters bilaterally (arrows), with no evidence of perinephric, peri-ureteric, intra-abdominal or pelvic collections. b Ultrasound scan of right kidney from case 1 . The right

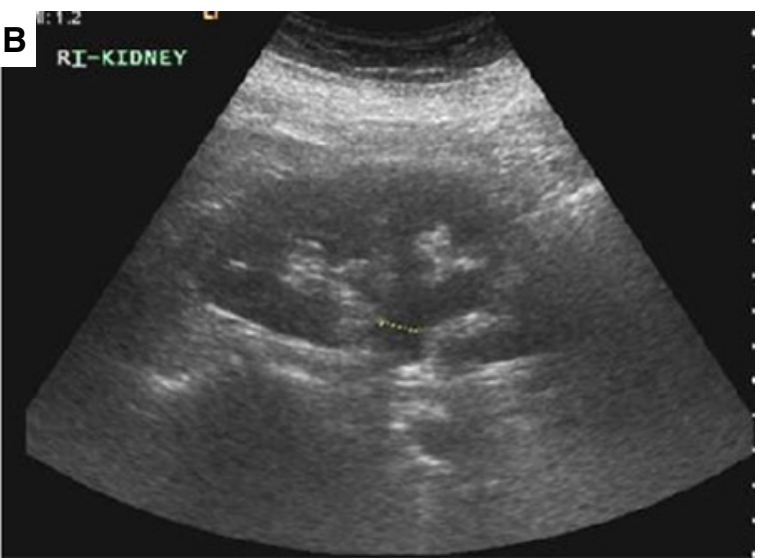

kidney measures $11.3 \mathrm{~cm}$ with normal renal parenchyma and no large focal abnormality but with mild dilatation of the pelvicalyceal collecting system. The renal pelvis measures approximately $10.9 \mathrm{~mm}$ at the pelvoureteric junction (dotted line), consistent with mild hydronephrosis. Similar findings were observed for the left kidney (not shown) 
preoperative cystoscopy and bilateral ureteric stenting. There were no intraoperative complications, and stents were inserted with ease and removed at the end of surgery. Post-operatively, she passed 1,800 $\mathrm{ml}$ of gross haematuria ( $24 \mathrm{~h}$ fluid balance: $2,000 \mathrm{ml} \mathrm{in} / 1,800 \mathrm{ml}$ out) but then became oliguric for 3 days (day 1 post-op $24 \mathrm{~h}$ fluid balance: $3,050 \mathrm{ml}$ in/ $180 \mathrm{ml}$ out, day 2: $2,200 \mathrm{ml}$ in/10 $\mathrm{ml}$ out, day 3: $450 \mathrm{ml}$ in $/ 375 \mathrm{ml}$ out), and biochemistry investigations revealed a creatinine of $537 \mu \mathrm{mol} / \mathrm{l}$ and a urea of $16.6 \mathrm{mmol} / \mathrm{l}$. A renal ultrasound performed on day 3 post-op showed no evidence of obstruction and only mild hydronephrosis. Both ureters were not noted to be dilated. She passed $3,700 \mathrm{ml}$ of urine on day 4 (day 4 post-op $24 \mathrm{~h}$ fluid balance: $1,300 \mathrm{ml} \mathrm{in} / 3,700 \mathrm{ml}$ out) and $400 \mathrm{ml}$ on day 5 (day 5 post-op $24 \mathrm{~h}$ fluid balance: $1,450 \mathrm{ml} \mathrm{in} / 400 \mathrm{ml}$ out) but then again became oliguric for the next 2 days (day 6 post-op $24 \mathrm{~h}$ fluid balance: $1,400 \mathrm{ml}$ in $/ 100 \mathrm{ml}$ out, day 7 post-op $24 \mathrm{~h}$ fluid balance: $2,500 \mathrm{ml} \mathrm{in} / 0 \mathrm{ml}$ out) (creatinine $602 \mu \mathrm{mol} / 1$ and urea $23.8 \mathrm{mmol} / \mathrm{l}$ ). Fortunately, she passed 71 of urine on day 8 , and her renal failure was self-resolved without the need for dialysis or further intervention.

\section{Discussion}

We describe three case reports of patients who had bilateral ureteric stents placed prior to gynaecological cancer surgery and developed post-operative oligo-anuria with clinically obstructive renal failure despite relatively normal radiological assessment. One case was self-resolved, and two cases required urgent re-stenting to relieve obstruction and regain normal renal function.

Development of oligo-anuria has been occasionally documented as a complication of ureteral catheterization, thought to be caused by transient ureteric obstruction following stent removal [7], and has been estimated as a rate of $0-7.6 \%$ for routine prophylactic ureteric catheterizations [8]. This transient obstructive phenomenon has been described as 'reflex anuria' defined as 'cessation of urine output from both kidneys in response to irritation or trauma to one kidney or ureter or severely painful stimuli to other organs' [9].

The mechanism for the oligo-anuria is not fully understood, but there is evidence that ureteric manipulation can result in reduced renal blood flow and glomerular filtration rate or a reflex spasm of renal arterioles [10]. Other studies suggest ureteric oedema as the cause of uretovesical junction obstruction and resulting anuria [6]. This theory would explain how re-stenting bypasses the oedema, relieves the obstruction and restores renal function. The majority of studies, however, involved colorectal surgery where ureteric stenting has a longer history and such complications are known to those surgeons. There are only two reports of reflex anuria involving ureteric stents in gynaecological surgery. Abu-Rustum et al. reported that 2 out of 38 hysterectomy cases had a transient rise in post-operative creatinine attributed to distal ureteric oedema and one needed re-stenting to resolve the anuria [3], whereas Wood et al. reported that 7 out of 92 patients had post-operative oligo-anuria [11]. In contrast, Kuno et al. reported 0 out of 469 patients with reflux anuria postgynaecological surgery [12].

Our case series provides further evidence for transient obstructive renal failure as a complication of ureteric catheterization in gynaecological surgery at a rate of $0.7 \%$. Whilst we cannot be absolutely certain of the exact aetiology of the oligo-anuria, we consider these to be cases of reflex oligoanuria as (1) radiologically there was either no abnormality or only mild hydronepthrosis without organic obstruction of the urinary tract, (2) it was rapidly resolved by re-stenting or selfresolving causing a large diuresis, and (3) it was not associated with hypovolaemia or nephrotoxic drugs and did not respond to fluid challenges. As routine prophylactic ureteric stenting prior to gynaecological surgery becomes more widespread, it is crucial that gynaecologists are aware of the more serious complications so as to take appropriate, timely action.

To aid in identification of cases of reflux anuria, postoperative measurement of serum urea and electrolytes may be useful to help evaluate ureteric patency; however, these parameters are commonly affected by factors other than obstruction, such as intraoperative blood loss, fluid replacement and nephrotoxic drugs. It is important to first try to exclude those causes of acute renal failure by fluid challenge and cessation of nephrotoxic drugs.

One way to reduce the possibility of reflux anuria is to use staged removal of stents over a 24-h period or longer [6]. Bothwell used staged removal of stents over $24 \mathrm{~h}$ (i.e. removal of the right stent immediately post-operatively and the left stent $24 \mathrm{~h}$ later) for 92 colorectal surgery patients and reported no cases of anuria [4], whereas Chou et al. removed bilateral ureteric catheters at the end of surgery for 1,583 patients and reported no complications directly related to the catheters [5]. The timing of stent removal is likely to be an important factor in the development of reflux anuria. Leaving the stents in for longer may indeed reduce complications but may require a longer post-operative stay or readmission for stent removal may incur increased cost and inconvenience for the patient. It may be that time of stent removal should be made on an individual case or individual institution basis taking into account all the above factors.

Whether or not ureteric stents should be used routinely prior to gynaecological surgery is still under debate. Nevertheless, for surgeons using stents either routinely or on a case-by-case basis, awareness of serious complications of stenting such as the oligo-anuria described here is essential to guide appropriate, timely action and preserve renal function. 
Conflict of interest Anita Merritt, Brett Winter-Roach, Ilze Zommere and Richard Slade declare that they have no conflict of interest.

For studies with human subjects, please include the following statement:

Declaration of consent All procedures followed were in accordance with the ethical standards of the responsible committee on human experimentation (institutional and national) and with the Helsinki Declaration of 1975, as revised in 2000 (5). Informed consent was obtained from all patients for being included in the study. No identifying information about the patients is included in the article.

Co-author's contributions AJM, IZ and BWR are responsible for the concept and design and execution of the study, AJM wrote the manuscript, and IZ, RJS and BWR were responsible for manuscript editing.

\section{References}

1. Carley ME, McIntire D, Carley JM, Schaffer J (2002) Incidence, risk factors and morbidity of unintended bladder or ureter injury during hysterectomy. Int Urogynecol J Pelvic Floor Dysfunct 13(1):18-21

2. Jha S, Coomarasamy A, Chan K (2004) Ureteric injury in obstetric and gynaecological surgery. Obstet Gynaecol 6:203-208
3. Abu-Rustum N, Sonoda Y, Balck D, Chi D, Barakat R (2006) Cystoscopic temporary ureteral catheterization during radical vaginal and abdominal hysterectomy. Gynecol Oncol 103:729-731

4. Bothwell W, Bleicher R, Dent T (1994) Prophylactic ureteral catheterization in colon surgery. Dis Colon Rectum 37:330-334

5. Chou M, Wang C, Lien R (2009) Prophylactic ureteral catheterization in gynaecologic surgery: a 12-year randomized trial in a community hospital. Int Urogynecol J Pelvic Floor Dysfunct 20:689-693

6. Sheik F, Khubchandani I (1990) Prophylactic ureteral catheters in colon surgery - how safe are they? Dis Colon Rectum 33:508-510

7. Levine R, Pollack H, Banner M (1982) Transient ureteral obstruction after ureteral stenting. Am J Roentgenol 138:323-327

8. Bienek J, Meade P (2012) Reflux anuria after prophylactic ureteral catheter removal: a case description and review of the literature. J Endourol 26:294-296

9. Sirota J, Narins L (1957) Acute urinary suppression after ureteral catheterization: the pathogenesis of 'reflex anuria'. N Engl J Med 257:1111-1113

10. Maletz R, Berman D, Peele K, Bernard D (1993) Reflex anuria and uremia from unilateral ureteral obstruction. Am J Kidney Dis $22: 870-873$

11. Wood EC, Maher P, Pelosi MA (1996) Routine use of ureteric catheters at laproscopic hysterectomy may cause unnecessary complications. J Am Assoc Gynecol Laparosc 3:393-397

12. Kuno K, Menzin A, Kauder H (1998) Prophylactic ureteral catheterization in gynecologic surgery. Urology 52:1004-1008 